\title{
In remembrance of Professor Mario Andreoli (1929-2016)
}

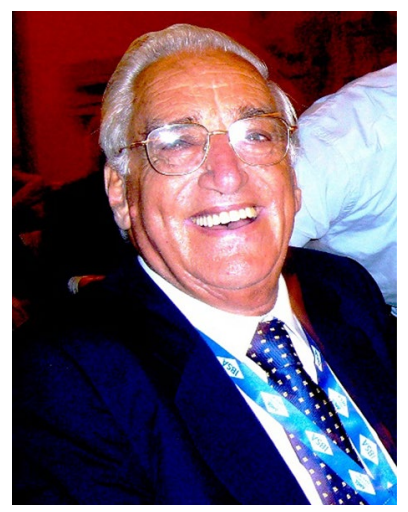

Prof. Mario Andreoli

On May, 9, 2016 Mario Andreoli, passed away in Rome. Born on August, 28, 1929 in San Lucido (CS), he was a fellow of Prof. Cataldo Cassano at the beginning at the Department of Internal Medicine of the University of Pisa and from 1956 at the II Department of Internal Medicine of the University of Rome.

He was the first Italian Endocrinologist to work from 1962 to 1963 with Jack Robbins in the prestigious Clinical Endocrinology Branch, N.I.A.M.D., National Institutes oh Health in Bethesda.

Back to Rome he founded an outstanding research group of scientists dedicated to thyroid pathophysiology.
He was the Secretary of the Fifth International Thyroid Conference, Rome, 24-27 May 1965, and Secretary of the European Thyroid Association from 1967 to 1971. He was the Founder and Director of the Thyroid Center, National Research Council of Italy, 1973-1980.

Associate Professor of Endocrinology at the University of Sassari, he then became Full Professor of Endocrinology at the University of Rome "La Sapienza" from 1980 to 2001. Emeritus Professor of the University of Rome "La Sapienza" from 2002.

He headed the 2nd Post-graduate School in Endocrinology of the University of Rome La Sapienza, and was the President of the Italian Society of Endocrinology from 1992 to 1994.

Prof Mario Andreoli contributed substantially to the study, development and growth of thyroid pathophysiology in Italy.

His lifelong passion and friendly attitude will be remembered by everyone.

$\mathrm{He}$ is survived by his wife Vittoria and his daughter Valeria.

The Alumni and Collaborators 